\title{
OPINION
}

\section{Defensive dentistry and the young dentist - this isn't what we signed up for}

\author{
A. Al Hassan'
}

In brief

Discusses the current state of dentistry.

Suggests young dentists will continue to leave the

profession.

Suggests steps to improve current climate and moral.

Why did I want to become a dentist? I wanted a job where I would be respected as a professional and could change the lives of others, using my hands. This, I thought, would be my ideal profession; one where I could walk into work with a smile on my face every day. Cue dental school a place where one is trained to become competent in all areas of general dentistry. As readers will appreciate, dentistry is a vast field and the question that comes to mind is how so many diverse and varied topics can be jam packed into a five-year course. There has always been a debate about what to put in, and therefore leave out. At my particular dental school, the first two years covered basic scientific theory, leaving three years to get into clinical dentistry with some 'other' aspects sprinkled in. Some of these aspects included general communication skills, record keeping and one or two practice visits at fancy dental practices to see how good life was as a general dental practitioner. In light of the profession's current climate and the rise of defensive dentistry, I aim to reflect on why many young graduates from all over the country feel out of touch with the profession so early on in their careers, and why some of these 'other' aspects of dentistry should have been covered much more comprehensively to prepare us for the big wide world.

\section{A massive wake-up call}

Leaving dental school and entering general practice was a massive wake-up call. Along with getting to grips with new techniques and materials, I quickly realised that there were other areas of dentistry which had to be understood to succeed in the profession; things that were not adequately taught in dental school. These included facets such as getting to grips with the business side of general practice in relation to the NHS and private systems, as well as being proactive and aware of the incredibly litigious environment I was working in. Luckily, my training practice was fantastic and I thoroughly enjoyed my year despite the steep learning curve. While networking, however, I

Llantarnam Dental, Lantarnam Road, Cwmbran, NP44 3BH United Kingdom

Correspondence to: Ali Al Hassan

Email: alhassan01@gmail.com

Refereed Paper. Accepted 1 September 2017

DOI: $10.1038 /$ sj.bdj.2017.982 came into contact with many young dentists who felt vulnerable, stressed and upset in the current system. The disappointing thing was that the causes for these anxieties were almost never the dentistry itself; rather it was the fear and implications of overzealous complaints with the overarching GDC and financial issues.

It has become clear to me this year that as dentists we are working in a pressure cooker where we have to constantly look over our shoulders and worry about when, not if, we will be brought before the GDC or civil courts over some triviality. Dentists have unanimously cried out that the GDC's processes are heavy handed and incredibly stressful for dentists. Even with the introduction of case examiners - meant to sieve out the inappropriate concerns - little has changed. I still hear of colleagues being dragged through the coals over minor infractions which have nothing to do with public safety. If anything, they do the opposite as the professional being unfairly investigated is subject to so much stress and mental degradation that their patient care will inevitably suffer. The whole profession begins to act much more defensively as a result, leading to worse outcomes again for patients.

\section{The impact of defensive dentistry}

The effects of defensive dentistry are plain to see; clinicians will routinely deny treatments which they could reasonably offer but wouldn't due to the risk of a possible escalating complaint, even despite mentioning all the risks and gaining 'valid' consent. I see more and more young graduates going into dental core training in the hospital; a much more sheltered environment than general practice where the health board acts as a shield for the individual, and therefore professionals can practise without looking over their shoulders and with less stress. This has led to a shortage of associates in some areas in the UK and therefore less general dental services being provided to the public. Added to this are the many legal firms, which make it their public mission to find errors in dental work, 
advertising in mainstream media outlets. On a side note, this is only compounded by the appearance that the traditional indemnity organisations seem only too happy to settle or pay out, feeding these firms to bring more cases forward. This may be why I see many dentists starting to leave the mainstream indemnity outlets for guaranteed representation packages.

Cases being brought by patients are on the rise at an accelerating rate with no end in sight. These issues play on the mind of the professional during all patient interactions and beyond, causing them to alter the way that they would otherwise do things, sometimes to the detriment of the best interests of patients. Many young dentists have simply up and left; Australia seems a much more attractive option where professionals can focus on and enjoy the dentistry itself, rather than worrying about all of these external factors. This leads to poor value for the tax payer, who pays to train these dentists up, and again a lesser provision of service to the public.

\section{Falling out of love with dentistry}

I do believe this environment is unsustainable, but for the time being, organisations and, in my view, universities, must prepare young would-be graduates better. Communication and the psychology of dental care should not be a side seminar; it must be a main module. Time and again we have seen cases where patients have not gone down the litigation route just because they have a great relationship with their dentist; whether that be not complaining at all or resolving the dispute locally which is most appropriate anyway. This trust relationship is as crucial in the management of patients as the treatments themselves, especially in the current climate. It is this relationship which along with contemporaneous, accurate notes of 'valid' consent to treatment, provides the strongest defence against complaints and further proceedings. To these points undergraduates should get much more in-depth training on communication, complaints handling, stress management and financial planning. Only then can young graduates enter the working world with something they are plainly lacking: confidence, and therefore contentment.

We can't let this continue. I have countless colleagues who are falling out of love with this wonderful profession; a profession dedicated to helping, curing and treating others. It is easy to lose sight of why we wanted to become dentists in the first place in this climate of stress and fear. We are on the cusp of a mental health crisis - online forums where anonymous posters can seek advice and support for their individual issues are only becoming more and more crowded. I credit my family and my tough upbringing as the reason for my relative resilience against these factors and being able to keep my smile up every day, but there are so many who are suffering in silence. Something must give, and if it isn't the inappropriate conditions, regulation and climate we work in, it will be the young human beings in this profession. 